\title{
Effect of structured physical activity on prevention of serious fall injuries in adults aged 70-89: randomized clinical trial (LIFE Study)
}

\author{
Thomas M Gill, ${ }^{1}$ Marco Pahor, ${ }^{2}$ Jack M Guralnik, ${ }^{3}$ Mary M McDermott, ${ }^{4}$ Abby C King, ${ }^{5}$ Thomas W Buford, ${ }^{2}$ \\ Elsa S Strotmeyer, ${ }^{6}$ Miriam E Nelson,7 Kaycee M Sink, ${ }^{8}$ Jamehl L Demons, ${ }^{8}$ Susan S Kashaf, ${ }^{1}$ \\ Michael P Walkup, ${ }^{9}$ Michael E Miller, ${ }^{9}$ for the LIFE Study Investigators
}

${ }^{1}$ Department of Medicine, Yale School of Medicine, Adler Geriatric Center, 874 Howard Avenue, New Haven, CT 06510 , USA

${ }^{2}$ Department of Aging and Geriatric Research, University of Florida, Gainesville, FL, USA

${ }^{3}$ Department of Epidemiology and Public Health, University of Maryland School of Medicine, Baltimore, MD, USA

${ }^{4}$ Departments of Medicine and Preventive Medicine,

Northwestern University

Feinberg School of Medicine, Chicago, IL, USA

${ }^{5}$ Departments of Health Research \& Policy and

Medicine, Stanford School of Medicine, Stanford, CA, USA

${ }^{6}$ Department of Epidemiology, University of Pittsburgh School of Public Health, Pittsburgh, PA, USA

${ }^{7}$ Friedman School of Nutrition Science and Policy, Tufts University, Boston, MA, USA

${ }^{8}$ Department of Medicine, Wake Forest School of Medicine, Winston-Salem, NC, USA

${ }^{9}$ Department of Biostatistical Sciences, Wake Forest School of Medicine, Winston-Salem, NC, USA

Correspondence to:

TM Gill thomas.gill@yale.edu Additional material is published online only. To view please visit the journal online (http://dx.doi. org/10.1136/bmj.i245)

Cite this as: BMJ 2016;352:i245 http://dx.doi.org/10.1136/bmj.i245

Accepted: 17 December 2015

\section{ABSTRACT}

OBJECTIVE

To test whether a long term, structured physical activity program compared with a health education program reduces the risk of serious fall injuries among sedentary older people with functional limitations. DESIGN

Multicenter, single blinded randomized trial (Lifestyle Interventions and Independence for Elders (LIFE) study).

\section{SETTING}

Eight centers across the United States between February 2010 and December 2013.

\section{PARTICIPANTS}

1635 sedentary adults aged $70-89$ years with functional limitations, defined as a short physical performance battery score $\leq 9$, but who were able to walk $400 \mathrm{~m}$.

\section{INTERVENTIONS}

A permuted block algorithm stratified by field center and sex was used to allocate interventions.

Participants were randomized to a structured, moderate intensity physical activity program $(n=818)$ conducted in a center (twice a week) and at home (3-4 times a week) that included aerobic, strength, flexibility, and balance training activities, or to a health education program $(n=817)$ consisting of workshops on topics relevant to older people and upper extremity stretching exercises.

\section{MAIN OUTCOME MEASURES}

Serious fall injuries, defined as a fall that resulted in a clinical, non-vertebral fracture or that led to a hospital admission for another serious injury, was a prespecified secondary outcome in the LIFE Study. Outcomes were assessed every six months for up to 42 months by staff masked to intervention assignment. All participants were included in the analysis.

\section{WHAT IS ALREADY KNOWN ON THIS TOPIC}

Serious fall injuries are some of the most dreaded and debilitating conditions experienced by older people

Data on whether serious fall injuries can be prevented are lacking from randomised trials

\section{WHAT THIS STUDY ADDS}

A structured physical activity program, compared with a health education program, did not reduce the risk of serious fall injuries among sedentary older persons

These null results were accompanied by suggestive evidence that the physical activity program may reduce the rate of fall related fractures and hospital admissions in men

\section{RESULTS}

Over a median follow-up of 2.6 years, a serious fall injury was experienced by $75(9.2 \%)$ participants in the physical activity group and $84(10.3 \%)$ in the health education group (hazard ratio $0.90,95 \%$ confidence interval 0.66 to $1.23 ; \mathrm{P}=0.52$ ). These results were consistent across several subgroups, including sex. However, in analyses that were not prespecified, sex specific differences were observed for rates of all serious fall injuries (rate ratio $0.54,95 \%$ confidence interval 0.31 to 0.95 in men; $1.07,0.75$ to 1.53 in women; $P=0.043$ for interaction), fall related fractures (0.47, 0.25 to 0.86 in men; $1.12,0.77$ to 1.64 in women; $\mathrm{P}=0.017$ for interaction), and fall related hospital admissions ( $0.41,0.19$ to 0.89 in men; $1.10,0.65$ to 1.88 in women; $\mathrm{P}=0.039$ for interaction).

\section{CONCLUSIONS}

In this trial, which was underpowered to detect small, but possibly important reductions in serious fall injuries, a structured physical activity program compared with a health education program did not reduce the risk of serious fall injuries among sedentary older people with functional limitations. These null results were accompanied by suggestive evidence that the physical activity program may reduce the rate of fall related fractures and hospital admissions in men.

TRIAL REGISTRATION

ClinicalsTrials.gov NCT01072500.

\section{Introduction}

Each year, 30\% of community living older people fall, and $20-30 \%$ of those who fall experience moderate to severe injuries. ${ }^{1-4}$ Among those aged 70 and older, falls are the leading cause of fatal and non-fatal injuries. ${ }^{5}$ In 2010, 2.3 million non-fatal fall injuries were treated in US emergency departments, and more than 662000 of these patients were admitted to the hospital. ${ }^{5}$ Falls among older people cost \$28.2b ( $€ 19.5 b$; €26b) each year in the USA, and most of this cost is incurred by injurious falls leading to hospital admission. ${ }^{6}$ Fall injuries are independently associated with subsequent disability in important activities, such as bathing and shopping, and with increased risk of long term admissions to nursing homes. ${ }^{78}$

Despite the cost and morbidity associated with serious fall injuries, data on prevention of these events are lacking from randomized trials. Several exercise based interventions have shown a reduction in falls, ${ }^{9-11}$ but none had sufficient statistical power to show a reduction in serious fall injuries.

The Lifestyle Interventions and Independence for Elders (LIFE) study recently reported that a structured 
moderate intensity physical activity program significantly reduced the primary outcome of major mobility disability compared with a health education program, among 1635 sedentary men and women aged 70-89 with functional limitations. ${ }^{12}$ The LIFE Study is the largest trial to evaluate the benefits of physical activity in older people. Serious fall injury was included in the LIFE Study as one of the prespecified secondary outcomes. By improving gait, balance, and lower extremity strength, ${ }^{13}$ physical activity may reduce the likelihood of falling and sustaining a serious injury, but it may also increase opportunities to fall and incur a serious injury. Here we report results associated with our hypothesis that a long term physical activity program compared with a health education program reduces the risk of serious fall injuries among sedentary older people with functional limitations. We also report results for additional analyses that were not prespecified. The results of several other secondary outcomes from the LIFE Study have been published elsewhere. ${ }^{121415}$

\section{Methods}

\section{Trial design and participants}

The LIFE Study was a multicenter, single blinded randomized trial conducted at eight field centers across the USA between February 2010 and December 2013. Details of the methods are published elsewhere. ${ }^{16}$ Men and women aged 70-89 were eligible if they were sedentary (reported $<20 \mathrm{~min} /$ week in past month performing structured physical activity (that is, exercise), and $<125$ $\mathrm{min} /$ week of moderate physical activity); had functional limitations, as evidenced by a short physical performance battery score 9 or less out of 12 (the short physical performance battery is an integrative measure of gait, balance and lower extremity strength); ${ }^{17}$ could walk $400 \mathrm{~m}$ in 15 minutes or less without the help of someone or a walker; had no major cognitive impairment (modified mini-mental state examination ${ }^{18}$ score 1.5 standard deviations below education specific and race specific norms); and could safely participate in the intervention as determined by medical history, physical exam, and electrocardiography. The primary recruitment strategy was targeted mass mailings to the community. ${ }^{19}$ The methods and procedures of the LIFE Study were refined based on the results and participant input from an earlier pilot study. ${ }^{13}$

The institutional review boards at all participating sites approved the study protocol, available on request at www.thelifestudy.org/public/index.cfm. We obtained written informed consent from all participants.

\section{Randomization}

Participants were randomized to a physical activity or health education program (see appendix figure 1) through a secure web based data management system using a permuted block algorithm (with random block lengths) stratified by field center and sex.

\section{Interventions}

The two interventions, which lasted 24 to 42 months depending on the time of enrollment, are described elsewhere. ${ }^{16}$ The physical activity intervention consisted of walking, with a goal of $150 \mathrm{~min} /$ week; strength; flexibility; and balance training. ${ }^{16}$ The intervention included two center based visits a week and home based activity 3-4 times a week. The physical activity sessions were individualized and progressed toward a goal of 30 minutes of walking at moderate intensity, 3-5 minutes of large muscle group flexibility exercises, 10 minutes of primarily lower extremity strength training by means of ankle weights (two sets of 10 repetitions), and 10 minutes of balance training. The participants began with light intensity and gradually increased intensity over the first two to three weeks of the intervention. On average the physical activity group attended $63 \%$ of the scheduled sessions: median $71 \%$ (interquartile range 50-83\%). ${ }^{12}$

The health education group attended weekly workshops during the first 26 weeks and monthly sessions thereafter. Workshops covered topics of relevance to older people, such as negotiating the healthcare system, traveling safely, and preventive services. The program also included a five to 10 minute instructor led program of stretching exercises. On average the health education group attended $73 \%$ of the scheduled sessions: median $82 \%(63-90 \%){ }^{12}$

\section{Data collection}

Participants returned every six months for follow-up. Assessment staff were blinded to the intervention. Race and ethnicity were reported by the participants and were collected according to the requirements of the National Institutes of Health. The short physical performance battery was reassessed at 6, 12, 24, and 36 months, and physical activity at 6, 12, and 24 months. Self reported physical activity was assessed with the community healthy activities model program for seniors questionnaire (CHAMPS), ${ }^{20}$ administered by unblinded staff, and objective physical activity was assessed by accelerometry over seven days (Actigraph; Pensacola, FL). ${ }^{12}$

For the purpose of safety monitoring, unblinded staff recorded falls and serious fall injuries occurring during intervention sessions. These events were not included in the outcomes assessment unless ascertained by blinded staff.

\section{Outcomes assessment}

We defined serious fall injury as a fall resulting in a clinical, non-vertebral fracture or that led to hospital admission for an injury. A fall was defined as an unexpected event in which the participant came to rest on the ground, floor, or lower level. ${ }^{11}$

Potential serious fall injuries were ascertained every six months through three questions: Since (last visit date), did a doctor tell you that you fractured or broke a bone? (If yes) Did you break a bone as a result of a fall? and Other than the conditions we just asked you about, were you admitted to a hospital overnight for any other reasons since (last visit date)? Two experts blinded to group randomization subsequently reviewed and adjudicated independently relevant 
medical records, including those from all hospital admissions. If the reviewers disagreed, they discussed the case. If they still disagreed, the information was forwarded to the adjudication committee, which arrived at consensus.

A definite fall related fracture required the fulfillment of four criteria: ${ }^{21}$ radiologic evidence of a non-vertebral, non-stress fracture; ${ }^{11}$ report of a fall within one week of injury; absence of major trauma or periprosthetic fracture; and no evidence of pathologic fracture. The non-fracture serious fall injuries required hospital admission and one of the following: non-fracture head injury with loss of consciousness, bleeding by neuroimaging, major facial trauma, or other comparable sequela; consequences of a long lie, such as rhabdomyolysis, dehydration or volume depletion, or hypothermia; or other fall injury, such as a severe sprain.

As an additional outcome, which was not prespecified, we evaluated falls that led to persistent restricted activity, defined as affirmative responses to two questions: Since (last visit date), have you fallen? and, Did this fall result in an inability to leave home for at least one week? The inclusion of this outcome allowed us to ascertain fall related events that were likely clinically important but did not meet the operational definition of a serious fall injury.

\section{Patient involvement}

No patients were involved in setting the research question or the outcome measures, nor were they involved in developing plans for recruitment, design, or implementation of the study. No patients were asked to advise on interpretation or writing up of results. There are no plans to disseminate the results of the research to study participants or the relevant patient community.

\section{Statistical analysis}

We based the sample size for the LIFE Study on power for the primary outcome of major mobility disability. Given this sample size, the power required for detecting differences between the two intervention groups in serious fall injuries was based on preliminary data from the LIFE pilot study. ${ }^{13}$ Adopting a two sided type 1 error of 0.05 , assuming a $3 \%$ annual incidence rate of serious fall injuries in the health education group and $8 \%$ annual loss to follow-up, the planned sample size of 800 participants for each group yielded $80 \%$ and $90 \%$ power to detect relative hazard ratios of 0.54 and 0.49 , respectively.

We tested the effect of the intervention on time until the first post-randomization serious fall injury based on a two tailed significance of 0.05 using the intention to treat approach. Event times were defined as the time from randomization until the adjudicated fall date, and censoring times were defined as the time from randomization until the last fall assessment or death. We used the Nelson-Aalen estimator to obtain cumulative incidence curves by intervention group. To compare interventions, we estimated hazard ratios with 95\% confidence intervals and used likelihood ratio tests from Cox proportional hazards regression models, with the baseline hazard stratified by sex. We chose a priori not to stratify by field center owing to the relatively small number of anticipated serious fall injuries. Using Fine and Gray's approach for fitting proportional subdistribution hazard models to survival data with competing risks, we performed a sensitivity analysis considering death as a competing risk. ${ }^{22}$

The types of serious fall injuries were enumerated for the two intervention groups, with the unit of measurement as people and injury. To compare the number of fractures, hospital admissions, and fractures or hospital admissions between groups, we calculated rate ratios (95\% confidence intervals) using a negative binomial model, with log transformed total follow-up time as an offset. A Lagrange multiplier test was used to evaluate whether the scale variable in this model was equal to 0 .

For serious fall injuries, we entered interaction terms into the Cox model (that is, separate models for each subgroup analysis) and used likelihood ratio tests to assess the consistency of the intervention effect across levels of four prespecified subgroups (age, sex, race/ ethnicity, and physical performance) and one post hoc subgroup (self reported fall in the year before randomization). When analyzing the sex interaction, we did not stratify the baseline hazard by sex. Because a clinically meaningful, although non-significant, interaction was observed for sex, we completed several post hoc analyses including calculating cumulative incidence curves separately by sex; including all prespecified subgroup factors in the model when evaluating the effect of sex on the incidence of serious fall injuries; and evaluating the interaction between sex and the intervention for all serious fall injuries, fall related fractures, and fall related hospital admissions.

We calculated the proportion of participants with at least one fall leading to persistent restricted activity by intervention group. Risk ratios (95\% confidence intervals) and a test for an interaction between intervention group and sex were obtained using Poisson regression, with log transformed follow-up time as an offset. We also used these methods to compare the risk of any fall over the entire follow-up period.

To understand better the sex specific results, we compared self reported and objectively measured physical activity between men and women by intervention group during the first two years of follow-up, which was the minimum duration of the intervention. For the self reported measure, we focused on walking and strength training activities. For the objective measure, we evaluated moderate activity based on accelerometry, using a definition of 760 counts/min..$^{23}$ We compared short physical performance battery scores between men and women by intervention group during follow-up. For each outcome, we used linear contrasts within the framework of mixed effects models to compare the average visit specific intervention effect for men versus women.

Finally, we calculated rates for falls and serious fall injuries that occurred during the physical activity and health education sessions. 


\begin{tabular}{|c|c|c|}
\hline Characteristics & $\begin{array}{l}\text { Physical activity } \\
(\mathrm{n}=818)\end{array}$ & $\begin{array}{l}\text { Health education } \\
(\mathrm{n}=817)\end{array}$ \\
\hline Mean (SD) age (years) & $78.7(5.2)$ & $79.1(5.2)$ \\
\hline Age $\geq 80$ & $341(41.7)$ & $362(44.3)$ \\
\hline Women & $547(66.9)$ & $551(67.4)$ \\
\hline \multicolumn{3}{|l|}{ Race/ethnicity: } \\
\hline White, non-Hispanic & $604(73.8)$ & $635(77.7)$ \\
\hline Black, non-Hispanic & $163(19.9)$ & $125(15.3)$ \\
\hline Hispanic & $31(3.8)$ & $30(3.7)$ \\
\hline Other & $20(2.4)$ & $27(3.3)$ \\
\hline Education beyond high school & $544(66.6)$ & $550(67.7)$ \\
\hline Mean (SD) No of chronic conditions & $2.0(1.2)$ & $2.0(1.2)$ \\
\hline Hypertension & $573(70.5)$ & $578(71.5)$ \\
\hline Diabetes & $199(24.4)$ & $216(26.6)$ \\
\hline Myocardial infarction & $60(7.4)$ & $69(8.5)$ \\
\hline Stroke & $57(7.0)$ & $52(6.4)$ \\
\hline Chronic pulmonary disease & $130(16.0)$ & $123(15.2)$ \\
\hline Cancer & $178(21.9)$ & $192(23.6)$ \\
\hline Mean (SD) No of prescription drugs & $5.3(3.4)$ & $5.4(3.3)$ \\
\hline Fall in past year & $412(50.4)$ & $404(49.4)$ \\
\hline Fall receiving medical attention in past year & $106(26.0)$ & $83(20.6)$ \\
\hline Mean (SD) body mass index & $30.1(5.7)$ & $30.3(6.2)$ \\
\hline Mean (SD) 3MSE score & $91.5(5.5)$ & $91.6(5.3)$ \\
\hline \multicolumn{3}{|l|}{ SPPB score: } \\
\hline Mean (SD) score & $7.4(1.6)$ & $7.3(1.6)$ \\
\hline Score $\leq 7$ & $353(43.2)$ & $378(46.3)$ \\
\hline
\end{tabular}

We did not control for the increased risk of type I error resulting from multiple testing of the secondary and exploratory endpoints, instead viewing them as providing useful information that can potentially bolster interpretation of results for the primary endpoint, a position that has previously been expressed as reasonable in clinical trials. ${ }^{24}$ All analyses were performed in SAS (SAS Institute), version 9.4 .

\section{Results}

Baseline characteristics of the two intervention groups were comparable (table 1). About half of the participants reported at least one fall in the past year. A larger proportion in the physical activity group reported a fall that required medical attention.

Over a median follow-up of 2.6 years, a serious fall injury was experienced by 75 (9.2\% of 818 ) participants in the physical activity group and $84(10.3 \%$ of 817$)$ in the health education group (hazard ratio 0.90, 95\% confidence interval 0.66 to $1.23 ; \mathrm{P}=0.52$ ) (fig 1). The results were unchanged when death $(n=42$ in physical activity group and $n=37$ in health education group) was accounted for as a competing outcome. Table 2 provides the types of serious fall injuries. No significant differences were observed in rates of all serious fall injuries (rate ratio $0.87,95 \%$ confidence interval 0.65 to $1.18)$, fall related fractures ( $0.87,0.63$ to 1.19$)$, or fall related admissions to hospital $(0.78,0.51$ to 1.20$)$ for the physical activity group compared with the health education group.

In subgroup analyses, hazard ratios for time to first serious fall injury did not differ significantly according

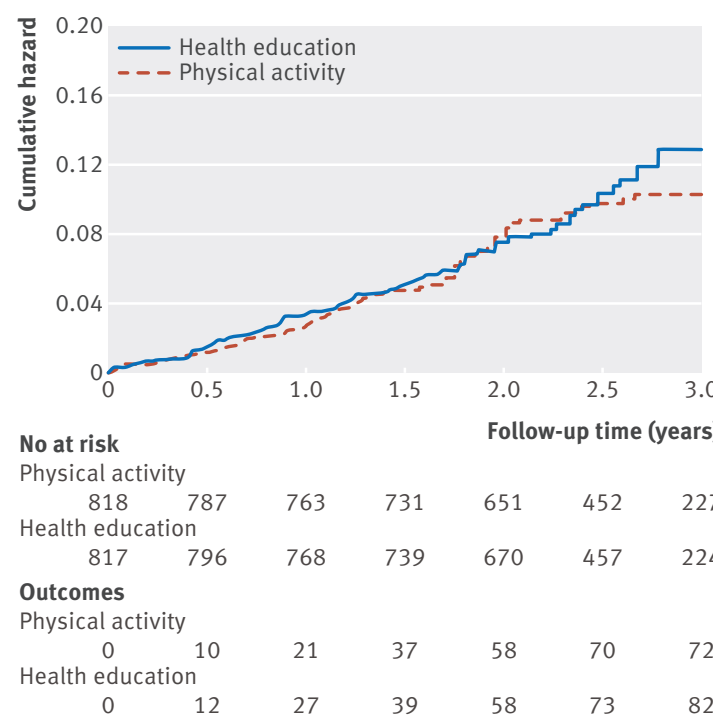

Fig 1 Effect of a moderate physical activity intervention on time to first serious fall injury. Outcomes represent the cumulative number of participants with a serious fall injury. The adjusted hazard ratio was obtained from a proportional hazards regression model that stratified the baseline hazard by sex. Curves were truncated at three years because of the small number of subsequent outcomes and people at risk. See table 2 for numbers of all outcomes through the end of follow-up (3.5 years). Duration of follow-up differed because participants were recruited over a 21 month period, but follow-up ended for all participants in December 2013

to age, sex, race/ethnicity, fall in past year, or baseline physical performance (fig 2). However, a clinically meaningful quantitative difference was observed for sex, with a hazard ratio of 0.62 (95\% confidence interval 0.34 to 1.12 ) in men and 1.05 (0.72 to 1.52 ) in women (fig 3). Over the entire follow-up period, 6.6\% (18 of 271) of the men in the physical activity group versus $10.5 \%$ (28 of 266) in the health education group experienced at least one serious fall injury; the corresponding values for women were 10.4\% (57 of 547) and 10.2\% (56 of 551). When factors for all prespecified subgroups were included as covariates in the model containing the interaction term with sex, results were consistent with the more parsimonious model (men: 0.58, 0.31 to 1.04; women: $1.17,0.81$ to 1.70 ). Significant sex differences were observed for rates of all serious fall injuries (risk ratio $0.54,95 \%$ confidence interval 0.31 to 0.95 in men; $1.07,0.75$ to 1.53 in women; $\mathrm{P}=0.043$ for interaction), fall related fractures $(0.47,0.25$ to 0.86 in men; $1.12,0.77$ to 1.64 in women; $\mathrm{P}=0.017$ for interaction), and fall related admissions to hospital (0.41, 0.19 to 0.89 in men; 1.10, 0.65 to 1.88 in women; $\mathrm{P}=0.039$ for interaction). Appendix table 1 provides the types of serious fall injuries for men and women.

A fall leading to persistent restricted activity occurred in 47 (5.7\% of 818$)$ participants in the physical activity group and $71(8.7 \%$ of 817$)$ in the health education group, yielding a risk ratio of 0.66 (95\% confidence interval 0.46 to 0.94$)$. The reduction in fall related restricted activity did not differ $(\mathrm{P}=0.53$ for 
Table 2 | Types of serious fall injuries by intervention group. Values are numbers (percentages) unless stated otherwise

\begin{tabular}{|c|c|c|c|c|}
\hline \multirow[b]{2}{*}{ Types of injuries } & \multicolumn{2}{|c|}{ Physical activity $(\mathrm{n}=818)$} & \multicolumn{2}{|c|}{ Health education $(n=817)$} \\
\hline & People* & Injury & People* & Injury \\
\hline All serious fall injuries & $75(9.2)$ & 81 & $84(10.3)$ & 94 \\
\hline Fall related fractures: & $66(8.1)$ & 71 & $76(9.3)$ & 84 \\
\hline Facial & $3(4.5)$ & $3(4.2)$ & $6(7.9)$ & $6(7.1)$ \\
\hline Hand or finger & $5(7.6)$ & $5(7.0)$ & $8(10.5)$ & $8(9.5)$ \\
\hline Lower arm or wrist & $15(22.7)$ & $15(21.1)$ & $12(15.8)$ & $12(14.3)$ \\
\hline Elbow & $3(4.5)$ & $3(4.2)$ & $6(7.9)$ & $6(7.1)$ \\
\hline Upper arm & $6(9.1)$ & $6(8.5)$ & $12(15.8)$ & $13(15.5)$ \\
\hline Rib & $10(15.2)$ & $10(14.1)$ & $8(10.5)$ & $8(9.5)$ \\
\hline Pelvis & $2(3.0)$ & $2(2.8)$ & $5(6.6)$ & $5(6.0)$ \\
\hline Hip & $13(19.7)$ & $13(18.3)$ & $15(19.7)$ & $17(20.2)$ \\
\hline Upper or lower leg & $3(4.5)$ & $3(4.2)$ & $1(1.3)$ & $1(1.2)$ \\
\hline Knee & $2(3.0)$ & $2(2.8)$ & $6(7.9)$ & $6(7.1)$ \\
\hline Ankle & $5(7.6)$ & $5(7.0)$ & $3(3.9)$ & $3(3.6)$ \\
\hline Foot or toe & $4(6.1)$ & $4(5.6)$ & $4(5.3)$ & $4(4.8)$ \\
\hline Other & $4(6.1)$ & $4(5.6)$ & $3(3.9)$ & $3(3.6)$ \\
\hline Fall related admissions to hospital: & $36(4.4)$ & 37 & $44(5.4)$ & 48 \\
\hline Fracture & $27(75.0)$ & $27(73.0)$ & $35(79.5)$ & $38(79.2)$ \\
\hline Head injury & $5(13.9)$ & $5(13.5)$ & $7(15.9)$ & $7(14.6)$ \\
\hline Consequence of long lie & $2(5.6)$ & $2(5.4)$ & $3(6.8)$ & $3(6.3)$ \\
\hline Other serious injury & $4(11.1)$ & $4(10.8)$ & $6(13.6)$ & $6(12.5)$ \\
\hline
\end{tabular}

*For all serious fall injuries, fall related fractures, and fall related admissions to hospital, the denominator includes all participants randomized to the specific intervention group.

tDenominator includes all injuries for specific injury subtype. Some participants had more than one serious fall injury event, and some events included more than one type of injury.

\#The rates per 100 person years were 3.83 for all serious fall injuries, 3.36 for fall related fractures, and 1.75 for fall related hospital admissions.

\$Rates per 100 person years were 4.38 for all serious fall injuries, 3.92 for fall related fractures, and 2.24 for fall related admissions to hospital.

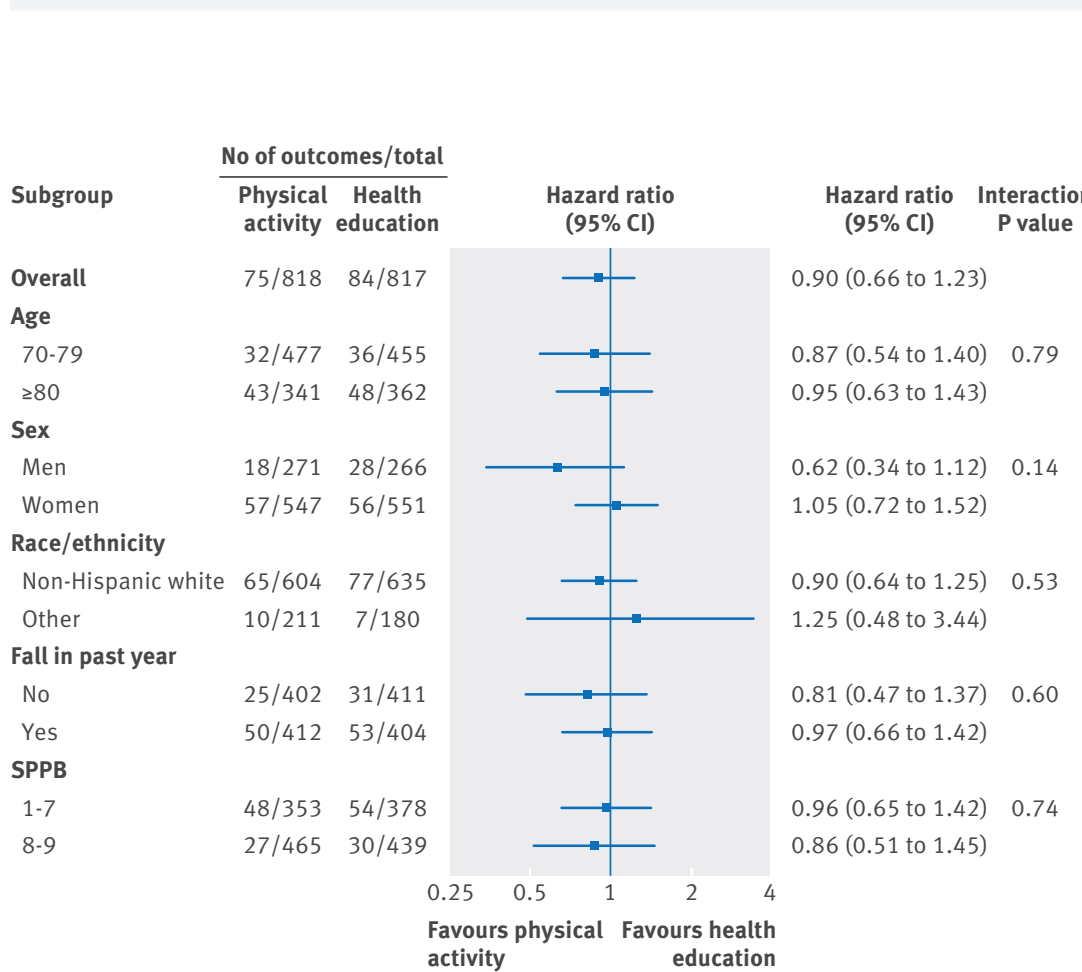

Fig 2 | Hazard ratios for time to first serious fall injury for physical activity versus health education according to subgroups. Age, sex, ethnicity/race, and baseline physical performance were prespecified in the analysis plan, whereas fall in past year was not. With the exception of the analysis for the sex subgroup effect, the adjusted hazard ratios were obtained from proportional hazards regression models that stratified the baseline hazard by sex. SPPB=short physical performance battery. $P$ values were obtained from likelihood ratios tests of the interaction terms added to the proportional hazards regression model

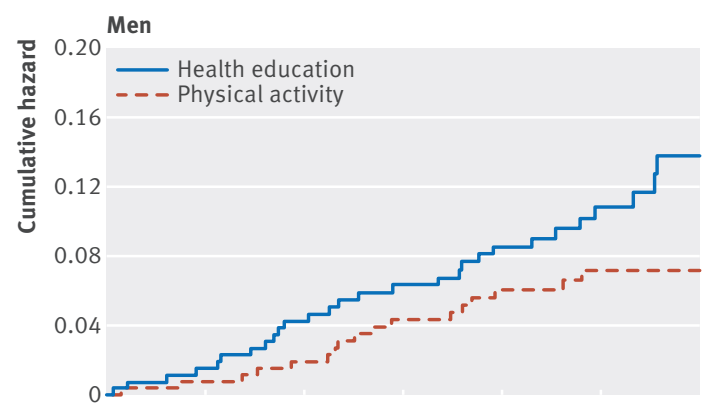

No at risk

Physical activity

$\begin{array}{lllllll}271 & 262 & 254 & 240 & 214 & 150 & 69\end{array}$ Health education

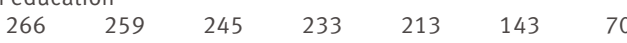

Outcomes

Physical activity

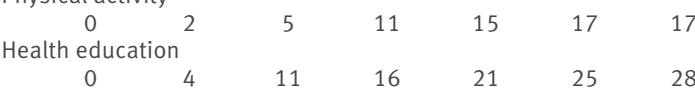
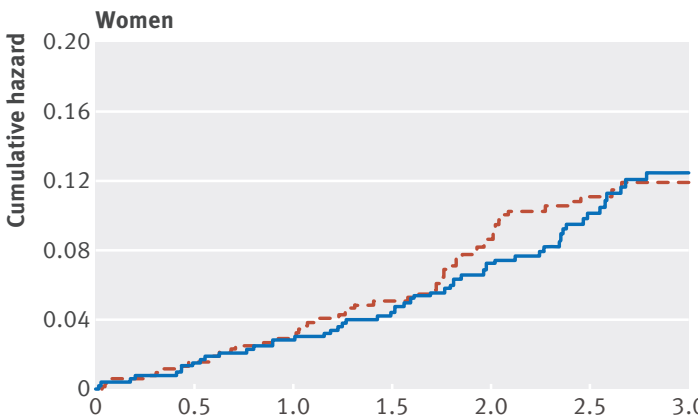

No at risk

Follow-up time (years)

Physical activity

$\begin{array}{cccccc}547 \quad 525 & 509 & 491 & 437 & 302 & 158 \\ \begin{array}{c}\text { Health education } \\ 551 \quad 537\end{array} & 523 & 506 & 457 & 314 & 154 \\ \begin{array}{c}\text { Outcomes } \\ \text { Physical activity } \\ 0\end{array} & & & & & \\ \begin{array}{c}\text { Health education } \\ 0\end{array} 8 & 16 & 26 & 43 & 53 & 55 \\ 8 & 16 & 23 & 37 & 48 & 54\end{array}$

Fig 3 | Effect of a moderate physical activity intervention on time to first serious fall injury in men and women. Outcomes represent the cumulative number of participants with a serious fall injury. Adjusted hazard ratios were obtained from proportional hazards regression models that included sex, intervention, and sexxintervention terms (that is, sex was not used as a factor to stratify the baseline hazard). The curves were truncated at three years because of the small number of subsequent outcomes and persons at risk. The numbers of all outcomes through the end of follow-up (3.5 years) are reported in appendix table 1

interaction) between men (0.54, 0.26 to 1.10 ) and women $(0.71,0.47$ to 1.07$)$. The difference in the percentage of participants reporting any fall between the physical activity (59.9\%) and health education (61.2\%) groups was small $(0.98,0.91$ to 1.06$)$ and did not differ by sex: $56.8 \%$ and $63.5 \%$ in men and $61.4 \%$ and $60.1 \%$ in women, respectively.

Based on mixed effects models fit to the CHAMPS questionnaire, the physical activity group averaged 104 more minutes (per week) in walking and strength training activities than the health education group. Although not statistically significant ( $\mathrm{P}=0.06$ for interaction), 
this differential was greater in men (120 minutes, 95\% confidence interval 100 to 140) than in women (96 minutes, 82 to 110). Based on accelerometry, the physical activity group averaged 40 more minutes (per week) in moderate physical activity than the health education group; this differential was greater in men (59 minutes, 39 to 80 ) than in women ( 31 minutes, 16 to 45 ; $\mathrm{P}=0.02$ for interaction). The follow-up short physical performance battery scores, adjusted for baseline scores, were greater for the physical activity group than for the health education group in men $(0.43,0.09$ to 0.73$)$ but not in women $(0.04,-0.21$ to 0.29$)$, although the test for statistical interaction was not significant $(\mathrm{P}=0.06)$. Discontinuation of the physical activity intervention did not differ significantly between men (17.0\%) and women $(13.2 \%)(\mathrm{P}=0.14)$.

Thirty falls and three serious fall injuries were reported during 114100 physical activity sessions, yielding rates per 100000 sessions of 26.3 and 2.6; and three and one, respectively, occurred during 37180 health education sessions, yielding rates of 8.1 and 2.7.

\section{Discussion}

The LIFE Study found no difference in the risk of serious fall injuries for a physical activity intervention versus a health education program among sedentary older people with functional limitations. The results were consistent across several subgroups, including sex. In analyses that were not prespecified, the physical activity program was more effective in reducing the rate of all serious fall injuries, including fall related fractures and admissions to hospital, in men than in women.

Despite being the largest and longest trial of physical activity in older people, ${ }^{19}$ the LIFE Study only had sufficient power to detect relatively large reductions in serious fall injuries. For the comparison of physical activity versus health education, the hazard ratio was 0.90 for serious fall injuries, which was a prespecified secondary outcome in the LIFE Study, and the rate ratio was 0.87 . These null results were accompanied by a statistically significant $34 \%$ reduction in falls leading to persistent restricted activity, a finding that did not differ significantly between men and women.

In contrast to women, who showed no benefit, men randomized to physical activity experienced a $46 \%$ reduction in all serious fall injuries, including a 53\% reduction in the rate of fall related fractures and a $59 \%$ reduction in the rate of fall injuries leading to admission to the hospital. Because the analyses were not prespecified, these sex specific results should be interpreted with caution and warrant replication in future studies. For comparisons between the two intervention groups, we found much larger differential increases in self reported and objectively measured physical activity in men than in women, providing one possible explanation for these results. Another possible explanation is that, in response to the physical activity program, men had greater improvements than women in their gait, balance, and muscle strength, as evidenced by their marginally greater benefit on short physical performance battery scores over time.

\section{Comparison with other studies}

A recent systematic review and meta-analysis of seven exercise based clinical trials reported a pooled rate ratio of 0.57 (95\% confidence interval 0.36 to 0.90 ) for serious fall injuries. ${ }^{25}$ Inconsistency across trials was deemed to be moderately large, with effect sizes ranging from 0.15 ( 0.02 to 1.16 ) to 0.94 ( 0.60 to 1.49$).{ }^{25}$ In contrast to interventions in these previous trials, the LIFE intervention was not designed specifically to prevent falls or serious fall injuries and may not have focused sufficiently on balance, a factor deemed to be important to the success of previous trials. ${ }^{25}$ None the less, the LIFE intervention has previously been shown to improve scores on the short physical performance battery, ${ }^{13}$ an integrative measure of gait, balance, and strength. Although an earlier systematic review and meta-analysis had raised concerns that increasing physical activity without adequate attention to balance might increase the risk of falling, ${ }^{26}$ we found no difference in the percentage of participants experiencing any fall between the physical activity and health education groups, despite large differences in physical activity between the groups, suggesting that balance training may have been adequate.

\section{Limitations and strengths of this study}

In addition to being underpowered to detect small, but possibly important reductions in the hazard of the prespecified outcome of first serious fall injury, our study has several other limitations. Firstly, the injurious fall outcome was limited to fractures and other serious fall injuries leading to hospital admission. These fall related injuries are associated with the greatest morbidity and costs. ${ }^{27}$ Furthermore, less severe injuries, such as bruises, cuts, and persistent pain, are more difficult to adjudicate since they may not receive medical attention or may be poorly documented in the medical record. Given the significant differences that were observed for falls leading to persistent restricted activity, it is possible that the physical activity program reduces the risk of any fall injury (serious and less severe). Secondly, the six month assessment interval may have led to under-ascertainment of fall related outcomes. Serious fall injuries, however, are much less susceptible to poor recall than are other falls. ${ }^{28}$ To enhance the ascertainment of serious fall injuries, medical records from all hospital admissions were reviewed and adjudicated. Thirdly, men represented only about a third of the study population, a value that is consistent with census estimates. Had a larger number of men been enrolled, the power to detect sex specific differences in the risk of a first serious fall injury by intervention group would have been enhanced. Fourthly, study participants were not recruited because of their fall risk, possibly leading to a diminished benefit of the intervention for the prevention of serious fall injuries. However, the physical activity program was no more effective among higher risk participants who reported a fall in the year before randomization or those 
who had more severe functional limitations. Finally, we did not control for type I error in this analysis of a prespecified secondary outcome and related outcomes that were not prespecified. This approach is consistent with the views of others, as the estimated effects sizes are trustworthy and useful even in the presence of an inflated type I error. ${ }^{24}$

Study strengths include the large and racially diverse sample of vulnerable older people from eight field centers spanning the USA, the rigorous methods to ascertain and adjudicate serious fall injuries, excellent retention, and adherence rates to the physical activity intervention that were similar or higher than those achieved in other shorter studies involving older people. ${ }^{29}$ In addition, because fewer than $5 \%$ of age eligible people were excluded on the basis of an underlying medical condition, our results should be broadly applicable to our target population of sedentary older people with functional limitations who do not already have major mobility disability.

\section{Clinical implications}

Our results should be interpreted in the context of the primary results from the LIFE Study, which showed an $18 \%$ reduction in the risk of major mobility disability, defined as loss of ability to walk $400 \mathrm{~m}$, and a $28 \%$ reduction in the risk of persistent mobility disability. ${ }^{12}$ Given the morbidity and costs associated with serious fall injuries, demonstrating a concomitant reduction in this distinct and clinically meaningful outcome would further enhance the public health relevance of the LIFE physical activity intervention. Results from the current study are mixed, with no overall reduction in the prespecified outcome of time to first serious fall injury, but a substantial decrease in the rate of all serious fall injuries, an outcome that was not prespecified, in men. As a recurrent event, the outcome of all serious fall injuries may have greater clinical relevance than that of time to first serious fall injury. The safety of the LIFE intervention is evidenced by the low rate of serious fall injuries during the physical activity sessions, a rate that was comparable to that during the health education sessions.

\section{Conclusions}

Our results do not support the benefit of structured moderate intensity physical activity in reducing the risk of serious fall injuries among sedentary older people with functional limitations. None the less, the safety and demonstrated benefit of the LIFE physical activity program in reducing major mobility disability, ${ }^{12}$ coupled with suggestive evidence from the current study for reduction of fall related fractures and hospital admissions in men, support continued evaluation of the program for possible widespread implementation in the community.

We thank Evan C Hadley and Sergei Romashkan from the National Institute on Aging (Bethesda, MD) for their substantial intellectual contribution to the development and implementation of the LIFE Study. ECH and SR are federal employees fully paid by the National Institutes of Health. They did not receive any additional compensation from the study. We also thank the participants of the LIFE Study for their important contributions.
Contributors: MEM had full access to all of the data in the study and takes responsibility for the integrity of the data and the accuracy of the data analysis. All authors participated in designing the analyses, interpreting the results, and writing the manuscript. All authors had full access to the data and are guarantors for the study.

Funding: This study was supported by cooperative agreement U01AG22376 from the National Institutes of Health (NIH) and National Institute on Aging; supplement U01AG022376 from the National Heart, Lung, and Blood Institute; and sponsorship in part from the Intramural Research Program. The research is partially supported by the Claude D Pepper Older Americans Independence Centers at the University of Florida (P30AG028740), Wake Forest University (P30AG21332), Tufts University (P30AG031679), University of Pittsburgh (P30AG024827), and Yale University (P30AG021342), and the NIH/NCATS CTSA at Stanford University (UL1RR025744), University of Florida (U54RR025208) and Yale University (UL1TR000142). Tufts University is also supported by the Boston Rehabilitation Outcomes Center (R24HD065688). LIFE investigators are also partially supported by the following: TMG is the recipient of an academic leadership award (K07AG3587) from the National Institute on Aging.

Competing interests: All authors have completed the ICMJE uniform disclosure form at http://www.icmje.org/coi_disclosure.pdf and declare: no support from any organization for the submitted work; no financial relationships with any organizations that might have an interest in the submitted work in the previous three years, no other relationships or activities that could appear to have influenced the submitted work.

Ethical approval: Each participating centers' institutional review board approved this study; all participants provided informed consent. Transparency: TMG and MEM affirm that the manuscript is an honest, accurate, and transparent account of the study being reported; that no important aspects of the study have been omitted; and that any discrepancies from the study as planned have been explained.

Data sharing: Information is available at www.thelifestudy.org/public/ index.cfm under the LIFE coded dataset access link.

This is an Open Access article distributed in accordance with the Creative Commons Attribution Non Commercial (CC BY-NC 3.0) license, which permits others to distribute, remix, adapt, build upon this work non-commercially, and license their derivative works on different terms, provided the original work is properly cited and the use is non-commercial. See: http://creativecommons.org/licenses/ by-nc/3.0/.

Quach L, Yang FM, Berry SD, et al. Depression, antidepressants, and falls among community-dwelling elderly people: the MOBILIZE Boston study. J Gerontol A Biol Sci Med Sci 2013;68:1575-81. doi:10.1093/gerona/glt084.

2 Srikanth V, Beare R, Blizzard L, et al. Cerebral white matter lesions, gait, and the risk of incident falls: a prospective population-based study. Stroke 2009;40:175-80. doi:10.1161/STROKEAHA.108.524355.

3 Tinetti ME, Doucette J, Claus E, Marottoli R. Risk factors for serious injury during falls by older persons in the community. I Am Geriatr Soc 1995;43:1214-21. doi:10.1111/j.1532-5415.1995.tb07396.x.

4 Centers for Disease Control and Prevention (CDC). Self-reported falls and fall-related injuries among persons aged $>$ or $=65$ years - United States, 2006. MMWR Morb Mortal Wkly Rep 2008;57:225-9.

5 Centers for Disease Control and Prevention. Web-based Injury Statistics Query and Reporting System (WISQARS). 2014. www.cdc. gov/injury/wisqars/.

6 Centers for Disease Control and Prevention. Cost of falls among older adults. 2015. www.cdc.gov/HomeandRecreationalSafety/Falls/ fallcost.html.

7 Tinetti ME, Williams CS. The effect of falls and fall injuries on functioning in community-dwelling older persons. / Gerontol A Biol Sci Med Sci 1998:53:M112-9. doi:10.1093/gerona/53A.2.M112.

8 Tinetti ME, Williams CS. Falls, injuries due to falls, and the risk of admission to a nursing home. N Engl J Med 1997;337:1279-84 doi:10.1056/NEJM199710303371806.

9 Province MA, Hadley EC, Hornbrook MC, et al. The effects of exercise on falls in elderly patients. A preplanned meta-analysis of the FICSIT Trials. Frailty and Injuries: Cooperative Studies of Intervention Techniques. JAMA 1995:273:1341-7. doi:10.1001/ jama.1995.03520410035023.

10 Gillespie LD, Robertson MC, Gillespie WJ, et al. Interventions for preventing falls in older people living in the community. Cochrane Database Syst Rev 2012:9:CD007146.

11 Lamb SE, Jørstad-Stein EC, Hauer K, Becker C. Prevention of Falls Network Europe and Outcomes Consensus Group. Development of a common outcome data set for fall injury prevention trials: the Prevention of Falls Network Europe consensus. J Am Geriatr Soc 2005;53:1618-22. doi:10.1111/j.1532-5415.2005.53455.x. 
12 Pahor M, Guralnik JM, Ambrosius WT, et al. LIFE study investigators. Effect of structured physical activity on prevention of major mobility disability in older adults: the LIFE study randomized clinical trial. JAMA 2014:311:2387-96. doi:10.1001/jama.2014.5616

13 Pahor M, Blair SN, Espeland M, et al. LIFE Study Investigators. Effects of a physical activity intervention on measures of physical performance: Results of the lifestyle interventions and independence for Elders Pilot (LIFE-P) study. J Gerontol A Biol Sci Med Sci 2006;61:1157-65. doi:10.1093/gerona/61.11.1157.

14 Sink KM, Espeland MA, Castro CM, et al. LIFE Study Investigators. Effect of a 24-month physical activity intervention vs health education on cognitive outcomes in sedentary older adults: the LIFE randomized trial. JAMA 2015;314:781-90. doi:10.1001/jama.2015.9617.

15 Groessl EJ, Kaplan RM, Sweet CM, et al. Cost-effectiveness of the LIFE physical activity intervention for older adults at increased risk for mobility disability. J Gerontol A Biol Sci Med Sci 2016; [forthcoming].

16 Fielding RA, Rejeski WJ, Blair S, et al. LIFE Research Group. The Lifestyle Interventions and Independence for Elders Study: design and methods. J Gerontol A Biol Sci Med Sci 2011;66:1226-37. doi:10.1093/gerona/glr123.

17 Guralnik JM, Simonsick EM, Ferrucci L, et al. A short physical performance battery assessing lower extremity function: association with self-reported disability and prediction of mortality and nursing home admission. J Gerontol 1994;49:M85-94. doi:10.1093/ geronj/49.2.M85.

18 Teng EL, Chui HC. The Modified Mini-Mental State (3MS) examination. J Clin Psychiatry 1987;48:314-8.

19 Marsh AP, Lovato LC, Glynn NW, et al. LIFE Study Research Group. Lifestyle interventions and independence for elders study: recruitment and baseline characteristics. J Gerontol A Biol Sci Med Sci 2013;68:1549-58. doi:10.1093/gerona/glt064.

20 Stewart AL, Mills KM, King AC, Haskell WL, Gillis D, Ritter PL. CHAMPS physical activity questionnaire for older adults: outcomes for interventions. Med Sci Sports Exerc 2001;33:1126-41. doi:101097/00005768-200107000-00010.

21 Black DM, Cummings SR, Karpf DB, et al. Fracture Intervention Trial Research Group. Randomised trial of effect of alendronate on risk of fracture in women with existing vertebral fractures. Lancet 1996:348:1535-41. doi:10.1016/S0140-6736(96)07088-2.
22 Fine JP, Gray RJ. A proportional hazards model for the subdistribution of a competing risk. J Am Stat Assoc 1999:94:496-509doi:10.1080/01621459.1999.10474144.

23 Matthew CE. Calibration of accelerometer output for adults. Med Sci Sports Exerc 2005;37(Suppl):S512-22. doi:10.1249/01. mss.0000185659.11982.3d.

24 Moyé LA. Multiple analyses in clinical trials: fundamentals for investigators.Springer-Verlag, 2010

25 El-Khoury F, Cassou B, Charles MA, Dargent-Molina P. The effect of fall prevention exercise programmes on fall induced injuries in community dwelling older adults: systematic review and metaanalysis of randomised controlled trials. BMJ 2013;347:f6234.

26 Sherrington C, Whitney IC, Lord SR, Herbert RD, Cumming RG, Close JC. Effective exercise for the prevention of falls: a systematic review and meta-analysis. J Am Geriatr Soc 2008;56:2234-43. doi:10.1111/j.1532-5415.2008.02014.X.

27 King MB, Tinetti ME. Falls in community-dwelling older persons. / Am Geriatr Soc 1995;43:1146-54. doi:10.1111/j.1532-5415.1995. tb07017.x.

28 Ganz DA, Higashi T, Rubenstein LZ. Monitoring falls in cohort studies of community-dwelling older people: effect of the recall interval. J Am Geriatr Soc 2005;53:2190-4. doi:10.1111/j.1532-5415.2005.00509.x

29 Ettinger WH Ir, Burns R, Messier SP, et al. A randomized trial comparing aerobic exercise and resistance exercise with a health education program in older adults with knee osteoarthritis. The Fitness Arthritis and Seniors Trial (FAST). JAMA 1997;277:25-31. doi:10.1001/jama.1997.03540250033028.

Appendix: figure showing flow of participants through study

Appendix: footnote to accompany appendix figure Appendix: research investigators for the LIFE Study Appendix: types of serious fall injuries by intervention group for men and women 